

\section{Sumário}

Dossiê TEMÁTICO: NOVOS INSTITUTOS JURÍDICOS DE LICITAÇÕES E CONTRATOS 17

I. LicitaÇõEs E CONTRATOS PÚBLICOS: PARTE GERAL. 18

INTEGRATED CONTRACT IN LAW 14.133/2021: NEW LAW, SAME PROBLEMS? A STUDY OF COMPARATIVE LAW .20

Paulo Afonso Cavichioli Carmona, Bruno Ribeiro Marques e Odilon Cavallari

Reajustamento de preços na Nova Lei de Licitações e Contratos Administrativos BRASILEIRA: O "Princípio" Da ANUALIDAde.

Ricardo Silveira Ribeiro e Bráulio Gomes Mendes Diniz

A nova Lei de Licitações, as encomendas tecnológicas e o diálogo competitivo .61 André Dias Fernandes e Débora de Oliveira Coutinho

LiCITAÇÕES, CONTRATOS E O IMPULSO À APRENDIZAGEM PROFISSIONAL: UM ESTUDO SOBRE A CONTRATAÇÃo de APRENDizes no ESTAdo do AMAZONAS, BRAsIL

Emerson Victor Hugo Costa de Sá, Natasha Yasmine Castelo Branco Donadon e Mauro Augusto Ponce de Leão Braga

Licitações, contratos e Modelo Brasileiro de Processo: notas sobre a viabilidade DA UTILIZAÇÃo DE FERRAMENTAS PROCESSUAIS PARA CONFERIR MAIOR EFICIÊNCIA ÀS AQUISIÇÕES PÚBLICAS

Claudio Madureira e Carlos André Luís Araujo

RESOlUÇão DE CONFLITOS COM A ADMINISTRAÇÃo PÚBLICA E A NOVA LEI DE LICITAÇÕES E CONTRATOS: REFORÇO DOS MEIOS ALTERNATIVOS.

Clarissa Sampaio Silva e Danille Maia Cruz

A Adesão do Brasil ao Acordo sobre Contratações Públicas da OMC: entre tabus e DIFICULDADES REAIS

Eduardo Ferreira Jordã e Luiz Filippe Esteves Cunha

II. Accountability e controle

A LEI N. ${ }^{\circ}$ 14.133/2021 E OS NOVOS LIMITES do CONTROLE EXTERNO: A NECESSÁRIA DEFERÊNCIA dos Tribunais de Contas em prol da Administração Pública .................................. 162 Ricardo Schneider Rodrigues

O CONTROLE DAS CONTRATAÇÕES PÚBliCAS E A NOVA LEI DE LICITAÇÕES: O QUE HÁ DE Novo? 183

Leandro Sarai, Flávio Garcia Cabral e Cristiane Rodrigues Iwakura 
Programa de compliance como exigênCia em licitações: ANálises EM Prol da QUALIFICAÇÃo DO PROCESSO LICITATÓRIO NO CONTEXTO DA LEI 14.133/2021.

Cristian Ricardo Wittmann e Anayara Fantinel Pedroso

A NOVA REALIDAde bRASILEIRA DE NECESSIDADE DE PROGRAMAS DE INTEGRIDADE DAS PESSOAS JURÍDICAS LICITANTES EM PROCESSOS LICITATÓRIOS DA ADMINISTRAÇÃO PÚBLICA 227

Fernando Silva Moreira dos Santos e Luiz Fernando de Oriani e Paulillo

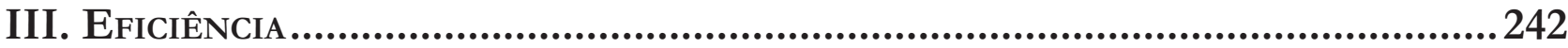

Efficiency contracts in the New Brazilian Procurement Law: conceptual FRAMEWORK AND INTERNATIONAL EXPERIENCE

Floriano de Azevedo Marques Neto, Hendrick Pinheiro e Tamara Cukiert

A gestão de riscos como instrumento para a aplicação efetiva do Princípio Constitucional dA EFICIÊNCIA.

Rafael Rabelo Nunes, Marcela Teixeira Batista Sidrim Perini e Inácio Emiliano Melo Mourão Pinto

IV. Contratação PÚblica No Direito ESTrangeiro

LA ADQUisición de VACUNAS CONTRA LA COVID-19 POR COLOMBIA: ENTRE LA CONFIDENCIALIDAD Y LA FALTA DE TRANSPARENCIA. 284

Gressy Kareny Rojas Cardona e David Mendieta

LA DISCRIMINACIÓN EX POST DE LOS OFERENTES DE UNA LICITACIÓN PÚBLICA COMO INFRACCIÓN ADMINISTRATIVA Y DE LIBRE COMPETÊNCIA 312 Jaime Arancibia Mattar

LA DISCRIMINACIÓN EX POST DE LOS OFERENTES DE UNA LICITACIÓN PÚBLICA COMO INFRACCIÓN ADMINISTRATIVA Y DE LIBRE COMPETÊNCIA..........................................................332 Udochukwu Uneke Alo, Obiamaka Adaeze Nwobu e Alex Adegboye

Outros Temas 348

I. Políticas públicas e institucionalidade

¿Existe El derecho humano a la identidad Cultural de los Migrantes en El Derecho INTERNACIONAL? 351 Juan Jorge Faundes e Glorimar Alejandra Leon Silva

El acceso a la justicia y el debido proceso ante el Tribunal Constitucional y la CorTe Suprema: dos NOCIONES DEL CONTENCIOSO ADMINISTRATIVO CHILENO .384 Pedro Harris Moya 
“Ministrocracia” E DECISÕES INDIVIDUAis CONTRAditórias No Supremo Tribunal FEDERAI

Ulisses Levy Silvério dos Reis e Emilio Peluso Neder Meyer

A POlÍtica de INOVAÇÃo COMO INSTRUMENTO DE REDUÇÃo DAS DESIGUALDADES REGIONAIS NO BRASIL

Caroline Viriato Memória e Uinie Caminha

Conflitos de Competência E A JudicializaÇão da Saúde no Federalismo Brasileiro.447 Jorge Leal Hanai, Luis Antônio Abrantes e Luiz Ismael Pereira

O Ministério Público no enfrentamento dos Reflexos da CRise da Covid-19: UMA

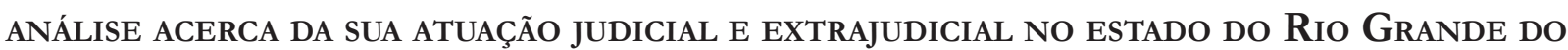
NorTE

Raquel Maria da Costa Silveira, Ana Mônica Medeiros Ferreira, Flávio Luiz Carneiro Cavalcanti e Haroldo Helinski Holanda

A CONSAgRaÇão CONSTITUCIONAL DA POlítica FALIMENTAR

Nuno de Oliveira Fernandes

II. Políticas públicas, grupos vulneráveis e litígios estruturais

LAS LIMITACIONES A LOS DERECHOS DE LOS GRUPOS VULNERABLES Y LOS SUJETOS DE ESPECIAL PROTECCIÓN DURANTE LA PANDEMIA Mary Luz Tobón Tobón

LitígIOS ESTRUTURAIS E A PROTEÇÃO DOS DIREITOS DOS POVOS INDÍGENAS DURANTE A PANDEMIA DE Covid-19: CONTRIBUições do ICCAL

Ana Carolina Lopes Olsen e Bianca M. Schneider van der Broocke

EPISTEMICÍDIO DAS NARRATIVAS NEGRAS E LITÍGIO ESTRUTURAL: INSTRUMENTOS EXTRAJUDICIAIS PARA DISSOLUÇÃO DO PROBLEMA NO SISTEMA EDUCACIONAL .......................................582

Vitor Fonsêca e Caroline da Silva Soares

Trajetórias E DiRETRIZES dAS POlíticas PÚbliCAS NACIONAIS PARA A POPULAÇão INFANTOJUVENIL EM SITUAÇÃO DE RUA...

Wânia Cláudia Gomes Di Lorenzo Lima, Cynthia Xavier de Carvalho e Maria Creusa de A. Borges

Emprendimiento como Fuente de Ingresos para las Víctimas del Conflicto Armado en el Marco de la Ley 1448 de Colombia. Reflexiones de la Implementación en el Valle del Cauca

Saulo Bravo García e Luz Marina Restrepo García

III. Políticas públicas e aÇão Restaurativa. 
JUSTIÇA RESTAURATIVA COMO AÇÃO COMUNICATIVA: EQUILÍBRIO ENTRE SISTEMA E MUNDO DA

Daniela Carvalho Almeida da Costa e Luciana Leonardo Ribeiro Silva de Araújo

JUSTIÇA RESTAURATIVA: ACORDOS E COOPERAÇÃO.................................................668

Samyle Regina Matos Oliveira e Selma Pereira de Santana 


\title{
Epistemicídio das narrativas negras e litígio estrutural: instrumentos extrajudiciais para dissolução do problema no sistema educacional*
}

\author{
Black narratives epistemicide and structural \\ litigation: extrajudicial instruments to solve the \\ problem in the educational system
}

\author{
Vitor Fonsêca** \\ Caroline da Silva Soares ${ }^{* * *}$
}

\section{Resumo}

O presente estudo analisa o epistemicídio das narrativas negras no sistema educacional brasileiro, que ainda persiste mesmo após a promulgação da Lei n. ${ }^{\circ}$ 10.639/2003, a qual torna obrigatório o ensino de História e Cultura Afro-Brasileira, com o objetivo de resgatar a contribuição do povo negro nas áreas social, econômica e política pertinentes à História do Brasil no currículo escolar. Com a utilização de levantamento bibliográfico dos últimos 5 (cinco) anos, em sua grande maioria, além do estudo de documentos legislativos e análise de dados publicados, investiga-se o epistemicídio como um litígio estrutural e a necessidade de reestruturação do aparelho educacional para interromper a produção dos danos apontados. Ao final, propõe-se a utilização de alguns instrumentos extrajudiciais existentes no processo civil coletivo brasileiro, que se mostram de grande contribuição para a dissolução do problema.

Palavras-chave: epistemicídio; litígio estrutural; educação; instrumentos extrajudiciais.

\section{Abstract}

This paper analyses the epistemicide of the black narratives in the Brazilian Educational System, which persists even after the enactment of Law no. 10.639/2003, which makes obligatory the teaching of Afro-Brazilian History and Culture, aiming to rescue the contribution of the black people at the social, economic and political areas concerning Brazilian History in the school curriculum. With the use of bibliographic survey from the last five years, other than the study of legislative history and data analysis, this paper investigates the epistemicide as a structural dispute and also the restructuring need of the educational apparatus to put a stop to the production of the aforementioned damages. Lastly, this paper proposes the use of some

*** Graduanda em Direito na Universidade do Estado da Bahia. Pesquisa realizada durante o Projeto "Afilhada(o) Acadêmica(o)" do Instituto Brasileiro de Direito Processual (IBDP).

E-mail: carolinesoares2@gmail.com.

Recebido em 03/04/2021

Aprovado em 11/06/2021

Doutor (PUC/SP). Professor e CoordenaManaus. Promotor de Justiça (AM).

E-mail: vitorfonseca@gmail.com. 
existing extrajudicial instruments of the Brazilian collective civil procedure, which present themselves as a great contribution to the dissolution of the problem.

Keywords: epistemicide; structural dispute; education; extrajudicial instruments.

\section{Introdução}

O objeto do presente estudo é o epistemicídio como nuance da inferiorização racial que pauta toda a ordem social instituída, especialmente no sistema educacional. Considerando-se como marco teórico o pensamento de Sueli Carneiro ${ }^{1}$, o epistemicídio trata do processo de múltiplas fontes de anulação e desqualificação da capacidade cognitiva, confiança intelectual e discriminação dos povos contra hegemônicos, sobretudo da população negra, fruto de um passado (muito presente) escravocrata e colonial, que resulta diversos danos na subjetividade e coletividade desses sujeitos.

A luta do Movimento Negro resultou na promulgação da Lei Federal n. ${ }^{\circ}$ 10.639/2003 que instituiu, ainda que tardiamente, no currículo escolar o ensino de História e Cultura Afro-Brasileira, o que poderia, em tese, contribuir com o combate ao epistemicídio. Entretanto, a referida lei não trouxe resultados significativos, devendo-se isso aos inúmeros fatores capazes de qualificar o problema como um litígio estrutural, haja vista o próprio funcionamento da estrutura educacional produzir violações de direitos individuais e coletivos. Por conseguinte, necessita-se de uma atuação conjunta dos legitimados e interessados por meio de múltiplos instrumentos, em especial, extrajudiciais, para resolução.

O objetivo deste estudo é justamente identificar esse epistemicídio como litígio estrutural e sugerir a utilização de instrumentos estruturantes para essa mudança paradigmática no ensino. Para isso, foram utilizados levantamento bibliográfico, estudo legislativo e análise de dados que evidenciam a perpetuação do problema relativo à estrutura educacional e propõem-se instrumentos extrajudiciais de atuação das instituições, sobretudo públicas, como alternativa para a construção de uma educação emancipadora.

Primeiramente, define-se o que é epistemicídio e suas consequências para população negra por meio de uma perspectiva histórica. Na sequência, mostram-se os caminhos que antecederam a promulgação da Lei n. ${ }^{\circ}$ 10.639/03, e, por fim, identifica-se o problema como um litígio estrutural e apresentam-se instrumentos extrajudiciais para sua dissolução.

\section{Epistemicídio: definição e consequências}

Inicialmente, é preciso tratar das diversas dimensões do racismo na estrutura global de civilização, pois toda organização social atual é fruto da construção histórica fundada nas disputas deflagradas ao decorrer do tempo. Partindo dessa premissa, o sequestro, o transporte e a escravização de africanos nas Américas influenciaram, diretamente, a construção desses sujeitos como pessoas humanas. Grosfóguel afirma que o epistemicídio foi inerente ao genocídio, uma vez que, durante o processo de escravização, os Outros - povos não hegemônicos, como aqueles vindos de África e nativos da terra - eram proibidos de pensar, rezar ou praticar suas cosmologias, conhecimentos e visão de mundo. Nesse cenário, a inferioridade epistêmica teria sido crucial para proclamar a inferioridade social biológica e posicionar os africanos abaixo da linha de humanidade. $^{2}$

\footnotetext{
${ }^{1}$ CARNEIRO, A. S. A construção do outro como não-ser como fundamento do ser. 2005. Tese (Doutorado) - Faculdade de Educação, Universidade de São Paulo, São Paulo, 2005. p. 97.

2 GROSFOGUEL, R. A estrutura do conhecimento nas universidades ocidentalizadas: racismo/sexismo epistêmico e os quatro genocídios/epistemicídios do longo século XVI. Sociedade e Estado, Brasília, v. 31, n. 1, abr. 2016.
} 
Em outras palavras, o processo genocida implicou o primeiro critério fundamental para a construção de papéis, lugares e níveis de poder da sociedade construída, a começar pela exploração das Américas, ou seja, a estruturação do modo básico de classificação universal de toda a população mundial. Além disso, o processo de colonização também teve duas implicações decisivas: povos despojados de suas identidades históricas (agora colonial e negativa) e exclusão da história da produção cultural desses povos para a humanidade. ${ }^{3}$ Njeri considera que esse processo foi uma quebra identitária e gerou o esvaziamento da pertença subjetiva ${ }^{4}$.

Dito isso, a realidade histórica de negação completa do Outro inclui a rejeição de seus saberes, cultura e trajetória, para que haja a construção desse novo sujeito colonizado, escravizado e racializado. Assim, dá-se início ao problema do epistemicídio. Nesse texto, o conceito de epistemicídio é alicerçado no pensamento de Sueli Carneiro que, ao aprofundar o conceito de Boaventura Sousa Santos, teoriza que tal processo é muito mais do que anulação e desqualificação do conhecimento dos povos subjugados, pois persiste na produção de indigência cultural na negação de acesso à educação, especialmente no que se refere à qualidade, pela produção de inferiorização intelectual, pelos mecanismos de deslegitimação do negro como portador e produtor de conhecimento, bem como pelo rebaixamento da capacidade cognitiva pela carência de material, somado ao comprometimento da autoestima pela discriminação no processo educativo. Dessa forma, "o epistemicídio fere de morte a racionalidade do subjugado ou a seqüestra, mutila a capacidade de aprender". ${ }^{5}$

Nesse processo, anteriormente à possível morte física desses corpos negros, morre o sujeito individual e coletivo pertencente a uma categoria política de identificação e identidade; para os agora categorizados como negros, após nova construção identitária racial, resta a negação de sua racionalidade. Como efeito dessa negação, é imposta nova concepção do "Ser", pautada na máxima da universalidade do conhecimento, caminhos e existência, resultando na criação da hegemonia e superioridade da visão ocidental de mundo, ou seja, eurocentrada, inicialmente pautada no viés religioso de justificação e agregado ao viés científico de discriminação.

Quão grave é a perda de uma identidade para um povo? As consequências são inúmeras e severas. A autora Sueli Carneiro, ao retomar a construção teórica de Santos, expõe que esse processo de supressão e privação intencional, chamados por ela de conhecimentos subjugados ou sepultados, resulta no empobrecimento irreversível do horizonte e das possibilidades de conhecimento e na liquidação sistemática das alternativas, seja no plano epistemológico ou no plano prático, quando não compatíveis com as práticas hegemônicas. ${ }^{6}$

A necessidade dessa retomada histórica é a seguinte: a prática epistemicida se reinventa. Ao classificar o Outro como inferior, liquidando tudo que lhe pertence, seja a cultura, práticas, conhecimentos incompatíveis com a hegemonia proposta, mesmo após a abolição da escravatura e todos os eventos e conquistas históricas dos povos colonizados, o epistemicídio permanece. Mudam-se as máscaras, porém o princípio é o mesmo: legitimar um único saber e aniquilar os saberes contra hegemônicos. À vista disso, suas características ressurgem com novas roupagens em todos os âmbitos da vida das pessoas racializadas, difundindo-se, também, no processo educacional.

Logo, os novos artifícios do epistemicídio, introjetado por meio da repetição e internalização dos paradigmas eurocêntricos, continua construindo os ideais de superioridade e inferioridade, ditando os lugares em que pertencem os descendentes de senhores e os descendentes de escravizados, ainda naturalizados pela história contada apenas sob a perspectiva dos senhores. Nesse sentido, Sueli Carneiro aponta que, após a abolição da escravatura e surgimento da república, sob influência do racismo científico "[e]ntram em cena

3 QUIJANO, A. A colonialidade do saber: eurocentrismo e ciências sociais. Buenos Aires: CLACSO, 2005. p. 127.

${ }^{4}$ NJERI, A. Reflexões artístico-filosóficas sobre a humanidade negra. Revista Ítaca, n. 36, p. 164-226, 2020. p. 168.

5 CARNEIRO, A. S. A construção do outro como não-ser como fundamento do ser. 2005. Tese (Doutorado) - Faculdade de Educação, Universidade de São Paulo, São Paulo, 2005. p. 97.

${ }^{6}$ CARNEIRO, A. S. A construção do outro como não-ser como fundamento do ser. 2005. Tese (Doutorado) - Faculdade de Educação, Universidade de São Paulo, São Paulo, 2005. p. 101. 
os procedimentos de contenção, exclusão, assimilação na relação dos negros com os processos educacionais frente à sua nova condição de liberto indesejável como cidadão"?

As dimensões de danos desse genocídio histórico vivido pelos africanos são inúmeras, identificadas por Njeri em vários campos: espiritualidade, herança, tradição, cultura, agência, identidade, economia, política, arte, moral, ética e educação. Como resultado, expõe que "os africanos sofrem o trauma histórico da sua desumanização e reproduzem as violências, contribuindo — e muitas das vezes facilitando o trabalho — para o genocídio". ${ }^{8}$ Com base nisso, propõe que a prática pedagógica deve considerar, intrinsecamente, o reflexo das consequências que ainda se fazem presente nos dias atuais, na qualidade, no acesso, na permanência ou também no conteúdo, sendo este o objeto deste artigo.

Dessa maneira, a educação antirracista e emancipadora deve preparar o sujeito negro para lucidez e criticidade diante da realidade que o acomete. Do mesmo modo, tem a incumbência de permitir sua autodeterminação e autoproteção enquanto ser humano. Ao definir o que seria educação emancipadora, Njeri elucida como sendo aquela que se preocupa com a pluralidade de formas de ser e estar no mundo, que abandona o olhar excludente único e homogeneizador universal da perspectiva eurocêntrica sobre a compreensão de educar. ${ }^{9}$

\section{0 apagamento de narrativas contra hegemônicas e a Lei $\mathbf{n}{ }^{\circ}$ $10.639 / 2003$}

Com a narrativa histórica acima proposta, identifica-se o aparelho educacional como fonte, como diz Sueli Carneiro, de múltiplos aniquilamentos ou subordinação da razão para os racialmente inferiorizados, ao condicioná-los numa posição de negação de seres produtores de conhecimento, tanto nos instrumentos pedagógicos como nas relações sociais no cotidiano escolar. ${ }^{10}$

Tais problemáticas estão também associadas aos conteúdos pedagógicos disseminados, ponto crucial para construção do pensamento que se propõe. Acerca deles, aponta-se que os conteúdos não aprendidos na escola, por omissão, cooperam com os processos de negação descritos. Assim, os conteúdos relativos à história dos processos políticos ditados pela racialidade, que poderiam servir de subsídio em prol das lutas emancipatórias, constituem-se de "saberes sepultados". ${ }^{11}$

Ribeiro, com base em Silva, aponta os materiais didáticos como fruto da neutralização histórica da colaboração dos povos negros na formação social, econômica e cultural brasileira. Neles, os Outros são vistos desempenhando papéis subalternos, o que pode contribuir para o desenvolvimento de um processo de autorrejeição e de rejeição ao seu grupo étnico/racial. ${ }^{12} \mathrm{O}$ resgate das narrativas contra hegemônicas para os alunos negros serviria para combater a sensação de inferioridade e a ausência de pertencimento social, construindo uma nova maneira de ser e estar na sociedade.

\footnotetext{
CARNEIRO, A. S. A construção do outro como não-ser como fundamento do ser. 2005. Tese (Doutorado) - Faculdade de Educação, Universidade de São Paulo, São Paulo, 2005. p. 102.

8 NJERI, A. Educação afrocêntrica como via de luta antirracista e sobrevivência na Maafa. Revista Sul-Americana de Filosofia e Educação (RESAFE), v. 31, p. 4-17, 2019. p. 7.

9 NJERI, A. Educação afrocêntrica como via de luta antirracista e sobrevivência na Maafa. Revista Sul-Americana de Filosofia e Educação (RESAFE), v. 31, p. 4-17, 2019. p. 7.

${ }^{10}$ CARNEIRO, A. S. A construção do outro como não-ser como fundamento do ser. 2005. Tese (Doutorado) - Faculdade de Educação, Universidade de São Paulo, São Paulo, 2005. p. 324.

11 CARNEIRO, A. S. A construção do outro como não-ser como fundamento do ser. 2005. Tese (Doutorado) - Faculdade de Educação, Universidade de São Paulo, São Paulo, 2005. p. 283.

12 RIBEIRO, K. Kemet, Escolas e Arcádeas: a importância da filosofia africana no combate ao racismo epistêmico e a Lei 10.639/03. 2017. Tese (Mestrado em Filosofia e Ensino) - Centro Federal de Educação Tecnológica, Rio de Janeiro, 2017. p. 33.
} 
Diante das marcas deixadas pelo passado escravocrata brasileiro, nos anos 1980, surgem diversos estudos que comprovaram o lugar do período escolar como o mais perverso na vida de pessoa negra, seja criança, jovem ou adulto. Nos anos 1990, as discussões se ampliaram, no que tange à educação, e a pauta foi incluída nos debates políticos do Movimento Negro. ${ }^{13}$

Com a tratativa em ebulição e por iniciativa do Movimento Negro, surgiu, como fruto da luta no Brasil, a Lei n. ${ }^{\circ} 10.639$ de 09 de Janeiro de 2003, a qual torna obrigatório o ensino de História e Cultura Afro-Brasileira em todo currículo escolar, em especial o estudo da História da África e dos Africanos, a luta dos negros no Brasil, a cultura negra brasileira e o negro na formação da sociedade nacional, para o resgate da contribuição do povo negro nas áreas social, econômica e política pertinentes à História do Brasil, nas áreas de Educação Artística e de Literatura e Histórias Brasileiras.

Em 2008, surgiu o Plano Nacional de Implementação das Diretrizes Curriculares Nacionais para Educação das Relações Étnico Raciais, Ensino de História e Cultura Afro-Brasileira e Africana ${ }^{14}$. Nesse mesmo ano, foi promulgada a Lei n. ${ }^{\circ} 11.645 / 08$, que legislou sobre a inclusão das narrativas dos povos indígenas, em sua cultura e história, nos estabelecimentos de ensino fundamental e de ensino médio, públicos ou privados.

O Plano traz como objetivos específicos: 1) desenvolver ações estratégicas para formação de professores para aplicação das leis; 2) colaborar e construir com os sistemas de ensino, conselhos educacionais, coordenações pedagógicas, gestores educacionais, professores e outros, políticas públicas e processos pedagógicos para implementação, promoção da pesquisa e produção de materiais didáticos e paradidáticos que valorizem a cultura afro-brasileira e diversidade; 3) colaborar na construção de indicadores para acompanhamento pelos poderes públicos e sociedade civil; 4) criar e consolidar agendas propositivas junto aos diversos atores do referido plano para disseminação dessas leis.

Por óbvio, a promulgação de Leis não garante sua efetividade. Ainda são muitos os desafios para alcançar o que é proposto. Entretanto, em geral, os autores estudados recebem a norma de maneira positiva. Ribeiro compreende a lei como ferramenta primordial para a reconstrução da imagem do continente africano, possibilitando, para a criança negra, referências positivas da sua história, tornando os alunos menos refratários à diversidade étnico-racial. ${ }^{15}$

Santos observa que a lei foi um reconhecimento da importância das lutas antirracistas dos movimentos sociais negros, bem como constata as injustiças e discriminações raciais contra os negros no Brasil e um pontapé para construção de ensino democrático. Porém, observa a lei como genérica, pois não garante uma implementação adequada ao não estabelecer metas para implementação, além de não tratar sobre a necessidade de qualificação dos docentes, nem de reformulação dos programas de ensino das universidades e cursos de graduação, principalmente os de licenciatura para formação de professores aptos para ministrarem História e Cultura Afro Brasileira. ${ }^{16}$

Siqueira Marques expõe que essa inclusão rompe com o silêncio da escola sobre a subalternização dos saberes dos afro-brasileiros, mito da democracia racial, racismo e preconceito racial. Do mesmo modo, a lei tensiona os docentes a adotarem práticas pedagógicas interculturais e a refletirem sobre a "legitimidade dos conhecimentos de matriz europeia e colonizadora por meio de currículos escolares hegemônicos e

\footnotetext{
13 RIBEIRO, K. Kemet, Escolas e Arcádeas: a importância da filosofia africana no combate ao racismo epistêmico e a Lei 10.639/03. 2017. Tese (Mestrado em Filosofia e Ensino) - Centro Federal de Educação Tecnológica, Rio de Janeiro, 2017. p. 27-28.

14 Informação extraída do portal do MEC. Disponível em: http://etnicoracial.mec.gov.br/images/pdf/diretrizes_curric_educ_etnicoraciais.pdf. Acesso em: 14 nov. 2020.

15 RIBEIRO, K. Kemet, Escolas e Arcádeas: a importância da filosofia africana no combate ao racismo epistêmico e a Lei 10.639/03. 2017. Tese (Mestrado em Filosofia e Ensino) - Centro Federal de Educação Tecnológica, Rio de Janeiro, 2017. p. 22.

16 SANTOS, S. A. A Lei 10.639/03 como fruto da luta anti-racista do Movimento Negro. In: BRASIL. Educação anti-racista: caminhos abertos pela Lei Federal n. 10.639/03. Brasília: MEC/SECAD, 2005. p. 21-37. p. 32-33.
} 
monoculturais". ${ }^{17}$ Há bastante tempo já se defende a necessidade de elaborar um currículo com base na "diversidade", com: a) formação adequada de professores; 2) planejamento de novos currículos; 3) desenvolvimento de materiais adequados e; 4) a análise e revisão crítica das práticas vigente ${ }^{18}$. Por fim, a lei suscita a reflexão para o currículo e formação do docente, no que tange à legitimação da lógica monocultural, subalternização da diferença, discriminação racial e preconceito.

Diante da perspectiva exposta, o instrumento legislativo, em geral, apresenta-se como proposta relevante e pertinente, mas infelizmente incompleta. Ademais, o Plano Nacional de Implementação das Diretrizes Curriculares Nacionais para a Educação das Relações Etnicorraciais e para ensino de História e Cultura Afrobrasileira e Africana apresenta-se como complemento da lei, mas não alcança a efetividade necessária para a mudança estrutural que o tema demanda, como será melhor detalhado nas próximas seções.

\section{0 epistemicídio nas escolas como um litígio estrutural}

O epistemicídio da população negra pode ser entendido como um litígio estrutural, seja pela perpetuação histórica, pelos danos irreparáveis e imensuráveis a esse grupo social, bem como pela legitimação das desigualdades raciais ao renegar a contribuição desses povos para formação social, econômica e cultural do Brasil, já identificada pela promulgação da Lei n. ${ }^{\circ}$ 10.639/03.

Essa conclusão pode ser extraída de uma das definições de litígios estruturais como litígios coletivos que decorrem da maneira em que uma estrutura burocrática opera. Com base nessa concepção, o próprio funcionamento da estrutura produz a violação de direitos que gera o litígio coletivo, seja pela causa, permissão ou perpetuação. Um ponto relevante é que, na hipótese de a violação ser apenas removida, há a possibilidade de somente ser aparentemente ou momentaneamente resolvido e também não serem observados resultados significativos, propiciando o ressurgimento do litígio no futuro. ${ }^{19}$

A complexidade do litígio envolvido e a maneira com que ele atinge subgrupos sociais distintos, com intensidade e formas diferentes, indicam a necessidade de alteração do funcionamento da estrutura que perpetua tal violação. Assim, caso não seja realizada mudança estrutural, o problema não será essencialmente resolvido e ainda haverá o risco de retorno ao estado anterior à tentativa de resolução ${ }^{20}$.

Esses litígios também são atravessados pela presença de violações estruturais de direitos, por meio de diversas práticas e dinâmicas institucionalizadas, resultado de uma causa complexa. Partindo desse ponto, as medidas estruturais, ao envolver conflitos multipolares de alta complexidade, têm a necessidade de reorganizar a instituição em totalidade, nos processos internos, estrutura burocrática e mentalidade de seus agentes ${ }^{21}$.

Ao fazer a intersecção das definições de litígio estrutural com o epistemicídio das narrativas negras no sistema educacional, depreende-se que o problema pode ser concebido como litígio estrutural. Já foi dito que o epistemicídio decorre do funcionamento da estrutura burocrática na qual a educação está inserida, sendo responsável pela permissão e perpetuação da violação. Ao tentar promover a sua dissolução somente ao promulgar a Lei Federal n. ${ }^{\circ}$ 10.639/03, o Estado não previu etapas para a implementação de resultados

\footnotetext{
17 MARQUES, E. P. S. A implementação da Lei 10.639/03 no Estado de Mato Grosso do Sul e a formação continuada de professores: uma perspectiva emancipatória e decolonial. Revista Contemporânea de Educação, v. 12, n. 23, p. 51-68, 2017. p. 53-56.

18 FREITAS, P. A Lei 10.639, o ensino de história e a cultura afro-brasileira. OPSIS, v. 10, n. 1, p. 15-28, 2010. p. 20.

19 VITORELLI, E. Levando os conceitos a sério: processo estrutural, processo coletivo, processo estratégico e suas diferenças. Revista de Processo, v. 284, n. 10, p. 333-369, out. 2018. p. 6-7.

20 VITORELLI, E. Levando os conceitos a sério: processo estrutural, processo coletivo, processo estratégico e suas diferenças. Revista de Processo, v. 284, n. 10, p. 333-369, out. 2018. p. 6-7.

21 NUNES, L. S. et al. Dos litígios aos processos estruturais: pressupostos e fundamentos. In: FARIA, J. C. et al. (org.). Novas tendências, diálogos entre direito material e processo. Belo Horizonte: Editora D’Plácido, 2018. p. 365-383. p. 368-369.
} 
significativos para o problema ser de fato resolvido. Dessa forma, permanece a violação de direitos do subgrupo social, relativa à população negra.

Ressalta-se que o ponto relevante se trata da necessidade de reorganização do aparelho educacional como um todo. Como o marco legislativo não trata dessas questões, o Plano supracitado apresenta o complemento para aplicação da Lei Federal nas escolas, que, em tese, supriria a problemática da efetividade do instrumento legislativo.

A pressão dos movimentos negros e, consequentemente, suas articulações com políticos mais sensíveis à questão racial brasileira tiveram como resultado a inclusão, por meio de leis setoriais, de disciplinas sobre a História dos Negros no Brasil e a História do Continente Africano nos ensinos fundamental e médio das redes estaduais e municipais de ensino. São ao todo sete Leis de Estados e Municípios, além do Distrito Federal, promulgadas em período anterior a legislação federal — entre 1989 e 1996 — que tratam sobre a inserção dos conteúdos nas escolas: Constituição do Estado da Bahia (5 de outubro de 1989), Lei Orgânica do Município de Belo Horizonte (21 de março de 1990), Lei n. ${ }^{\circ} 6.889$ (5 setembro de 1991) do município de Porto Alegre, Lei n. ${ }^{0} 7.685$ (17 de janeiro de 1994) do Município de Aracaju, Lei n. ${ }^{\circ} 2.639$ (16 de março de 1998) do Município de Teresina e a Lei n. ${ }^{\circ} 1.187$ (13 de setembro de 1996) do Distrito Federal. ${ }^{22}$

O advento de Leis Federais e leis locais, porém, não resolveu o problema do epistemicídio. Dados empíricos coletados por Siqueira Marques constatam concretamente que os velhos discursos epistemicidas ainda se fazem presentes no meio escolar. Os dados foram recolhidos por meio da equipe pedagógica da Rede Estadual de Ensino do Mato Grosso do Sul e contou com 572 profissionais, dentre professores do primeiro ao nono ano do ensino fundamental, gestores escolares, coordenadores pedagógicos, bibliotecários e assistentes de bibliotecas. ${ }^{23}$

A título de exemplo do estudo acima, destacam-se os seguintes depoimentos coletados na pesquisa:

a) sobre aspectos desfavoráveis à implementação da Lei;

Acho desfavorável, pelo fato de os próprios afro-brasileira, africana e indigena [serem] preconceituosos com eles mesmos. A época da discriminação acabou, mas eles insistem em achar que o mundo os despreza. E sobre os deficientes? E as pessoas especiais? Não têm importância? Têm leis? Têm. Têm acessibilidade? Têm. Mas o povo cumpre? Não!!! Essas pessoas são muito mais discriminadas do que o étnico-racial [...] (Professora de ciências) (grifos da autora). ${ }^{24}$

Outros depoimentos também relatam como desfavorável o número reduzido de aulas para cumprimento do conteúdo programado e ausência de desenvolvimento de projetos sobre diversidade cultural, além de declarações no sentido de "fica parecendo que o negro e o índio não conseguem se defender da sociedade existente. Pois, diante disso, a opressão continuará" e "A raça negra pode ser encarada como favorecida pelos demais alunos da unidade escolar". ${ }^{25}$

a) sobre as dificuldades à implementação da Lei apontadas;

As principais dificuldades apontadas como entraves à implementação dos conteúdos são a falta de capacitação da equipe escolar, acesso a fontes de pesquisa atualizadas, quantidade limitada de recursos didáticos e tecnológicos diante da demanda massiva de alunos. A falta de articulação entre as ações da Secretaria Esta-

\footnotetext{
22 SANTOS, S. A. A Lei 10.639/03 como fruto da luta anti-racista do Movimento Negro. In: BRASIL. Educação anti-racista: caminhos abertos pela Lei Federal n. 10.639/03. Brasília: MEC/SECAD, 2005. p. 21-37. p. 26-33.

23 MARQUES, E. P. S. A implementação da Lei 10.639/03 no Estado de Mato Grosso do Sul e a formação continuada de professores: uma perspectiva emancipatória e decolonial. Revista Contemporânea de Educação, v. 12, n. 23, p. 51-68, 2017. p. 62.

24 MARQUES, E. P. S. A implementação da Lei 10.639/03 no Estado de Mato Grosso do Sul e a formação continuada de professores: uma perspectiva emancipatória e decolonial. Revista Contemporânea de Educação, v. 12, n. 23, p. 51-68, 2017. p. 63.

25 MARQUES, E. P. S. A implementação da Lei 10.639/03 no Estado de Mato Grosso do Sul e a formação continuada de professores: uma perspectiva emancipatória e decolonial. Revista Contemporânea de Educaşão, v. 12, n. 23, p. 51-68, 2017. p. 64.
} 
dual de Educação, resistência dos professores ao tema e a falta de espaços eficientes para reflexão da prática também são considerados fatores importantes para a má aplicação do dispositivo legislado. ${ }^{26}$

b) preconceito e discriminação racial no contexto escolar.

Os depoimentos relacionados ao preconceito e à discriminação racial no contexto escolar mostram que há professores acreditando que, quanto mais o assunto é abordado, mais suscita preconceito, como também quanto mais é falado, mais tempo ele durará. Assim, acreditam que a lei na verdade tem um efeito oposto à proposta, e, inclusive, afirmam que a lei passa a ideia de existência de duas raças no mundo, o negro e o branco. $^{27}$

Esses dados levantados por Siqueira Marques não são isolados e foram confirmados por outros estudos. Em levantamento realizado com dez professores de $\mathrm{Geografia}^{28}$, muitos deles relataram que, ao falarem sobre a África, os alunos respondiam que havia fome no continente africano porque "eles são macumbeiros", evidenciando a influência religiosa sobre o preconceito dos próprios alunos. Em outro estudo descritivo, foi demonstrado que, durante treinamento de professores da rede pública, foram expostas as dificuldades dos professores em debater em sala de aula a ideia da miscigenação, não aquela romantizada da "democracia racial", mas aquela advinda do estupro de mulheres negras ${ }^{29}$.

A partir desses resultados, a pesquisa empírica demonstra duas nuances do dano em que a Lei Federal tenta mitigar: ausência de educação plural para formação de pessoas, principalmente aquelas que desenvolverão o papel educador, mas também explicita que, mesmo após 14 anos da promulgação do marco legislativo, problemas como as descontínuas políticas governamentais e a ausência de equipes capacitadas para garantir a formação continuada de professores nas secretarias de educação fazem com que esse litígio estrutural continue a ser perpetuado na estrutura educacional.

Assim, o problema persiste mesmo com a vigência da lei causando danos não somente à população negra, mas também aos sujeitos hegemônicos que são direcionados a produzir violências, reverberando discriminações e preconceitos de forma geral. Sendo assim, é de extrema necessidade uma mudança estrutural que fomente a grande virada paradigmática no combate à inferioridade racial instituída e possibilite, pelo viés educacional, uma possível recuperação da humanidade (de ser humano) dos povos contra hegemônicos, em especial da população negra. Reconhecer o papel do povo negro como sujeito humano "implica ruptura com o epistemicídio a fim de se produzirem formas de pensar/fazer conhecimento que viabilizem a autonomia dos indivíduos de modo a reverter toda forma de negação de sua dignidade" ${ }^{30}$.

\section{As estratégias estruturantes no combate ao epistemicídio nas escolas}

Com fundamento na premissa do racismo epistêmico no sistema educacional como litígio estrutural, depreende-se que apenas a promulgação de normas federais, estaduais ou municipais, ou até uma decisão judicial favorável que determine a aplicação dos dispositivos legislados, não será suficiente para corrigir um problema histórico, social e estrutural como foi apresentado.

\footnotetext{
${ }^{26}$ MARQUES, E. P. S. A implementação da Lei 10.639/03 no Estado de Mato Grosso do Sul e a formação continuada de professores: uma perspectiva emancipatória e decolonial. Revista Contemporânea de Educação, v. 12, n. 23, p. 51-68, 2017. p. 65.

27 MARQUES, E. P. S. A implementação da Lei 10.639/03 no Estado de Mato Grosso do Sul e a formação continuada de professores: uma perspectiva emancipatória e decolonial. Revista Contemporânea de Educaşão, v. 12, n. 23, p. 51-68, 2017. p. 65.

28 ROCHA, G. H. C. Dificuldades para implementação da Lei 10.639: a influência dos valores religiosos sobre os temas apresentados no texto da lei. Revista Tamoios, v. 7, n. 1, p. 51-59, 2011. p. 54.

${ }_{29}$ GILLAM, R. Learning to transgress: Law 10.639 and teacher training classrooms in São Paulo, Brazil. Transforming Anthropology, v. 24, n. 1, p. 70-79, 2016.

${ }^{30}$ NEVES, C. S. O lixo vai falar: racismo, sexismo e invisibilidades do sujeito negro nas narrativas de direitos humanos. Revista Brasileira de Politicas Públicas, v. 10, n. 2, p. 124-141, 2020. p. 133.
} 
Com base na compreensão de que os litígios complexos não comportam soluções simplistas, as chamadas "structural injunctions" apresentam-se como um importante instrumento, teorizado pela doutrina norte-americana, em que muitas decisões sobre questões coletivas demandam soluções que estão além da concepção tradicional processual de deferimento ou indeferimento, portanto, exigem "respostas difusas, com várias imposições ou medidas que se imponham gradativamente". ${ }^{31}$

Arenhart também evidencia a grande frequência com a qual são utilizados os chamados "provimentos em cascatas". O autor, ao tratar da perspectiva judicial do assunto, traz que é típico das medidas estruturais que haja uma primeira decisão, mais genérica, que fixará, de maneira geral, as diretrizes para proteção do direito, por conseguinte, posteriormente, exigirá que outras decisões sejam prolatadas, para solução de problemas e questões pontuais que surgem a partir da primeira decisão, mas também para especificar alguma ação necessária ${ }^{32}$. Isso demonstra a necessidade de acompanhamento contínuo do litígio estrutural. Afinal, não se constrói política pública, especialmente de desconstrução de práticas racistas, apenas com uma decisão judicial.

Para que atinja seu objetivo, a complexidade do litígio estrutural também exige participação das partes envolvidas de forma potenciada, para dar legitimidade às decisões e, mais importante, para que se atinja a solução ideal para o equacionamento do conflito. Dessa maneira, são de extrema relevância instrumentos de solução consensual, que valorizem o diálogo entre as partes, tais como: consultas, audiências públicas, admissão (solicitação oficiosa) de amici curiae, dentre outros. ${ }^{33}$

Nesse sentido, a atuação propulsora dos movimentos sociais negros e de intelectuais negros da área tem sido crucial para promoção de mudanças e inclusão dessas pautas mais subjetivas, mas como demonstradas de suma relevância para a formação de pessoas ${ }^{34}$. Dessa forma, o papel das consultas e audiências públicas relativo ao procedimento extrajudicial e dos amici curiae em relação ao procedimento judicial podem proporcionar, para além de uma maior legitimidade, uma verdadeira construção conjunta para atingir a finalidade. O amicus curiae, por exemplo, propulsiona efetiva atuação social em matérias de relevante interesse público, permitindo verdadeira participação política por meio do processo, ${ }^{35}$ além de promover a colheita de pareceres de especialistas os quais a Ciência Jurídica não poderá ofertar, de suma necessidade para o sucesso da intervenção jurisdicional. ${ }^{36}$

Em questões envolvendo políticas públicas como essa, visualiza-se, beneficamente, a celebração de convênios entre Ministério Público, Defensoria Pública e instituições públicas e/ou privadas para alcance de objetivos em comum. Há também a realização de convênios de cooperação técnica entre universidades, institutos científicos e órgãos públicos, bem como convênios de atuação integrada do Ministério Público com demais pactuantes, objetivando a promoção de determinadas políticas públicas. ${ }^{37}$

Destaca-se: o processo judicial não é primordial nem é o único caminho para a solução desse litígio estrutural, pois o processo civil coletivo brasileiro dispõe de uma série de instrumentos para resolução de litígios de forma extrajudicial, que auxiliam numa atuação menos burocrática que a judicial para solução das problemáticas coletivas e que buscam os mesmos objetivos de forma menos coercitiva para valorização do

\footnotetext{
31 ARENHART, S. C. Decisões estruturais no direito processual civil brasileiro. Revista de Processo, São Paulo, v. 225, n. 38, p. 389410, nov. 2013.

32 ARENHART, S. C. Decisões estruturais no direito processual civil brasileiro. Revista de Processo, São Paulo, v. 225, n. 38, p. 389410, nov. 2013.

33 NUNES, L. S. et al. Dos litígios aos processos estruturais: pressupostos e fundamentos. In: FARIA, J. C. et al. (org.). Novas tendências, diálogos entre direito material e processo. Belo Horizonte: Editora D’Plácido, 2018. p. 365-383. p. 372.

34 SANTOS, R. E. M. et al. Scales of political action and social movements in education: the case of the Brazilian Black Movement and Law 10.639. Globalisation, Societies and Education, v. 14, n. 1, p. 30-48, 2016.

35 CABRAL, A. P. Pelas asas de Hermes: a intervenção do amicus curiae, um terceiro especial. Revista de Direito Administrativo, Rio de Janeiro, v. 234, p. 111-142, out. 2003. p. 120.

${ }^{36}$ CARVAlHO, S. N. Processos coletivos e politicas públicas: mecanismos para a garantia de uma prestação jurisdicional democrática. 2013. Dissertação (Mestrado em Direito) - Faculdade de Direito, Universidade de São Paulo, São Paulo, 2013. p. $244-246$.

37 RODRIGUES, G. A. Ação Civil Pública e Termo de Ajustamento de Conduta: teoria e prática. 3. ed. Rio de Janeiro: Forense, 2011.
} 
diálogo na efetivação de direitos. Como se sabe, a busca por resultados mais efetivos deve garantir a primazia de meios extrajudiciais e deixar o judiciário para ser utilizado em caráter residual ou subsidiário ${ }^{38}$.

Por conseguinte, é de extrema importância a criação de mecanismos de diálogos entre as partes envolvidas, como as secretarias de educação, municipais e estaduais, os gestores públicos, docentes, usuários e grupos de interesses, como os movimentos sociais da causa negra, todos com papel fundamental para a promoção dos direitos agora reconhecidos nas legislações, como já demonstrado.

Nesse diapasão, entidades públicas, como o Ministério Público, por meio de uma atuação extrajudicial, podem buscar de maneira célere para a efetivação dos direitos fundamentais sociais por meio de procedimentos promovidos extrajudicialmente pelos agentes ministeriais, possibilitando a negociação com a Administração Pública ou com a iniciativa privada. Possibilita-se, então, que sejam dissolvidos os embaraços que mais dificultam a implementação da lei federal, como, por exemplo, "as demandas sociais, fixação de prazos e adequações orçamentárias" 39 .

\subsection{Audiências públicas}

A audiência pública mostra-se como um instrumento de suma importância para solucionar litígios que envolvem uma coletividade, pois o seu caráter consultivo garante a transparência e a participação dos atingidos pelas medidas a serem tomadas, com maior legitimidade e aproximação da realidade ${ }^{40}$. Por meio da audiência pública, em momento anterior à aprovação de projetos importantes ou de grande impacto social ou acerca das medidas de caráter geral, os envolvidos são chamados para debate oral e informal presidido pelo órgão responsável. ${ }^{41}$

Sendo assim, o instrumento é uma grande oportunidade de recolher junto à sociedade local e ao Poder Público os subsídios necessários para tomada de decisões e encaminhamentos acerca do litígio. Com a audiência pública, pode-se, então, identificar quais as exatas demandas sociais, ouvir os verdadeiros interessados no assunto e então instaurar procedimentos, elaborar Planos de Ação e Projetos Estratégicos Institucionais, para garantir a efetividade dos direitos e interesses da coletividade sem a necessidade de recorrer ao Judiciário ${ }^{42}$. Basta imaginar, por exemplo, o impacto de uma audiência pública com a participação do movimento negro para o resgate de pautas históricas e religiosas de uma comunidade local para elaboração de um plano pedagógico educacional de uma pequena cidade que somente valoriza datas comemorativas de heranças culturais eurocêntricas e de religiões judaico-cristãs, predominante no território nacional. Parece importante também pensar no papel de uma audiência pública sobre a avaliação pelos próprios professores, pais e alunos em torno do currículo efetivamente ensinado nas escolas, especialmente sobre aprendizados e pensamentos estereotipados sobre o continente africano, tais como a natureza da África como uma "selva tropical" ou da "civilização" trazida pelos europeus na época da colonização ${ }^{43}$.

\footnotetext{
38 ZENKNER, M. Ministério Público e solução extrajudicial de conflitos. In: RIBEIRO, C. V. A. (org.). Ministério Público: reflexões sobre princípios e funções institucionais. São Paulo: Atlas, 2010. p. 320.

39 CAMBI, E.; VASCONCELOS, J. A. Desjudicialização de políticas públicas e o Novo Código de Processo Civil: contributo do Ministério Público e da advocacia pública à solução extrajudicial de conflitos. A\&C - Revista de Direito Administrativo \& Constitucional, Curitiba, v. 16, n. 64, p. 225-251, abr. 2016. p. 241.

40 GRAVONSKI, A. A. Técnicas extraprocessuais de tutela coletiva: a efetividade da tutela coletiva fora do processo judicial. São Paulo: Editora Revista dos Tribunais, 2010. p. 329.

${ }^{41}$ RODRIGUES, G. A. Ação Civil Pública e Termo de Ajustamento de Conduta: teoria e prática. 3. ed. Rio de Janeiro: Forense, 2011.

${ }^{42}$ GRAVONSKI, A. A. Técnicas extraprocessuais de tutela coletiva: a efetividade da tutela coletiva fora do processo judicial. São Paulo: Editora Revista dos Tribunais, 2010. p. 331.

43 FREITAS, P. A Lei 10.639, o ensino de história e a cultura afro-brasileira. OPSIS, v. 10, n. 1, p. 15-28, 2010. p. 21.
} 


\subsection{Procedimento administrativo}

O Procedimento Administrativo (P.A.), regulamentado pela Resolução n. 174 do CNMP, é visto como mais flexível e capaz de resolver situações não tão bem definidas, com prazo mais longo que o inquérito civil. Sua finalidade é acompanhar e fiscalizar, de forma continuada, as políticas públicas ou instituições e também embasar atividades diversas daquelas sujeitas ao inquérito civil. ${ }^{44}$

$\mathrm{O}$ instrumento parte da colheita de informações, por meio de documentos, oitivas e reuniões técnicas. Assim, ao reunir dados relevantes para a atuação, o Ministério Público pode agir para promover ações que diminuam a inércia burocrática e/ou política, com a possibilidade de serem celebrados micro acordos nas reuniões, registrados em ata, que podem ser depois cobrados. Estes acordos são aptos a produzir melhoria do comportamento institucional de forma contínua e progressiva, promovendo a soma de esforços para encontrar soluções que levem a instituição a desenvolver melhor o seu papel. ${ }^{45}$

Por conseguinte, o P.A. pode promover reuniões técnicas com as secretarias de educação, em nível estadual ou municipal, para desenvolvimento de ações estratégicas de formação continuada de professores e criação de uma agenda com propostas para difundir os conteúdos. Do mesmo modo, o P.A. tem o potencial de atuar na construção de indicadores para acompanhamento pelos poderes públicos e sociedade civil do andamento da resolução do litígio. Como seu prazo é mais largo, o P.A. é instrumento adequado para o acompanhamento em longo prazo da implementação de políticas públicas como um litígio estrutural para a mudança de um currículo educacional e/ou capacitação de professores frente ao epistemicídio negro.

\subsection{Recomendação estrutural}

Outra possibilidade de atuação em problemas estruturais é a chamada Recomendação Estrutural, concebida como ato unilateral em que o Ministério Público noticia a sua perspectiva quanto à legalidade ou ilegalidade de uma conduta, ao passo que recomenda que ela seja modificada. Esse instrumento é garantido por meio da Lei Complementar n. ${ }^{\circ} 75 / 93$, artigo $6^{a}$, inciso XX, no qual é assegurada a competência do Ministério Público para expedir recomendações, tanto para melhora de serviços públicos, como na defesa de interesses, direitos e bens, fixando prazo razoável para adoção de providências. ${ }^{46}$

Esse instrumento não obriga o cumprimento dos termos pelo recomendado, porém atua como uma advertência formal no que diz respeito às possibilidades sancionatórias do descumprimento. ${ }^{47} \mathrm{~A}$ exigência de publicidade à recomendação e de uma resposta escrita e fundamentada ao membro do Ministério Público, dão não somente uma força moral, como também força política. ${ }^{48}$ Assim, quando focada no ponto central do problema e somada a um diálogo fortalecido com os gestores, pode impulsionar a transformação necessária para o rompimento da inércia que impedia a transformação e dissolução do litígio, em conjunto com os demais atores políticos e sociais. ${ }^{49}$

A Recomendação Estrutural pode declarar que os conteúdos suprimidos devem ser incluídos nos programas de ensino das universidades e cursos de graduação, como também impulsionar a cobrança em

\footnotetext{
${ }^{44}$ VITORELLI, E. Medidas estruturais extrajudiciais implementando mudanças estruturais pela via do consenso. In: VITORELLI, Edilson et al. Coletivização e unidade do direito. Londrina-PR: Editora Thoth, 2020. v. 2. p. 287-310. p. 296.

45 VITORELLI, E. Medidas estruturais extrajudiciais implementando mudanças estruturais pela via do consenso. In: VITORELLI, Edilson et al. Coletivização e unidade do direito. Londrina-PR: Editora Thoth, 2020. v. 2. p. 287-310. p. 297.

46 VITORELLI, E. Medidas estruturais extrajudiciais implementando mudanças estruturais pela via do consenso. In: VITORELLI, Edilson et al. Coletivização e unidade do direito. Londrina-PR: Editora Thoth, 2020. v. 2. p. 287-310. p. 297-298.

47 RODRIGUES, G. A. Ação Civil Pública e Termo de Ajustamento de Conduta: teoria e prática. 3. ed. Rio de Janeiro: Forense, 2011.

48 MAZZILLI, H. N. O inquérito civil: investigações do Ministério Público, compromissos de ajustamento e audiências públicas. São Paulo: Saraiva, 1999. p. 337-338.

49 VITORELLI, E. Medidas estruturais extrajudiciais implementando mudanças estruturais pela via do consenso. In: VITORELLI, Edilson et al. Coletivização e unidade do direito. Londrina-PR: Editora Thoth, 2020. v. 2. p. 287-310. p. 298-299.
} 
relação à reestruturação dos livros didáticos e paradidáticos, seja para aquisição daqueles já existentes que valorizam a pluralidade de saberes ou a promoção de pesquisa e produção desses conteúdos. Uma Recomendação Estrutural pode, por exemplo, sugerir a adoção de novos mapas e novas cartografias da região para as escolas, incluindo comunidades quilombolas e comunidades tradicionais, no lugar de "mapas oficiais", permitindo que os próprios grupos se mapeiem ${ }^{50}$, ou ainda sugerir a indicação prioritária de livros didáticos com conteúdos referentes a terras quilombolas (o que nem sempre acontece) ${ }^{51}$.

\subsection{Compromisso (ou termo) de ajustamento de conduta}

Outro instrumento possível é o Compromisso (ou Termo) de Ajustamento de Conduta (TAC), um acordo celebrado entre os legitimados coletivos públicos, conforme estabelecido na Lei n. ${ }^{\circ} 7.237 / 1985$, e os agentes da conduta considerada ilícita..$^{22} \mathrm{O}$ TAC possui dois efeitos principais, quais sejam: a determinação da responsabilidade pelo cumprimento do pacto firmado e a configuração de título executivo extrajudicial. ${ }^{53}$

Seria possível, por exemplo, que o Ministério Público e uma Secretaria Municipal firmassem consensualmente um TAC com objetivo de elaborar planos de ações estratégicas de implementação dos conteúdos propostos pelas Leis, seja para a construção de conselhos educacionais especializados, como a criação de políticas de formação continuadas de gestores de educação. Em nível federal, seria possível fomentar a reestruturação da matriz curricular de todos os cursos de graduação e licenciatura, com foco principal, em termos iniciais, naqueles que ministram História e Cultura Afro Brasileira. Mais importante: na celebração consensual do TAC, o próprio Poder Executivo pode indicar um cronograma com implementação de metas para o atendimento da lei federal e uma possível checagem de resultados futuros. Ninguém pode duvidar que um acordo consensual e bilateral como esse é melhor do que uma decisão adjudicada unilateralmente pelo Poder Judiciário.

\subsection{Notas sobre a atuação judicial}

Mesmo com todo esse aparato instrumental de técnicas extrajudiciais, a judicialização do litígio estrutural pode ser necessária. No entanto, essa iniciativa deve ser reservada apenas para o momento em que forem esgotados os instrumentos extrajudiciais de solução do litígio estrutural.

Por intermédio de uma Ação Civil Pública de caráter estrutural, poderão ser fixadas as diretrizes e as ações estratégicas de modo a suscitar a resolução do litígio, de forma a garantir o direito da população negra e promover a mudança social para a mitigação do epistemicídio nas escolas. Com base em uma decisão estrutural que constate o estado de desconformidade com o conteúdo programático, há o estabelecimento de um marco de ilegalidade e uma meta a ser atingida. Após isso, inicia-se a etapa das medidas para alcance do objetivo determinado. Os autores salientam que, para obter êxito nesse segundo momento, é fundamental a estipulação de prazo, modo e grau de reestruturação a ser implementado, regime de transição e a forma pela qual será realizada a avaliação/fiscalização permanente das medidas estruturantes. ${ }^{54}$

Instrumentos como a litigância estratégica coletiva, após não obtenção de êxito nas tratativas extrajudiciais, pode ser favorável em caso de litígios estruturais. Basta observar o Caso Creche em São Paulo, em que

\footnotetext{
${ }^{50}$ BOYNARD, L. M. Por uma desconstrução única de mundo: alternativas cartográficas para aplicação da Lei 10.639. Revista Tamoios, v. 7, n. 1, p. 113-124, 2011. p. 119.

${ }^{51}$ CORREA, G. S. Conteúdos possíveis a partir da Lei 10.639: as geografias das comunidades remanescentes de quilombo no território brasileiro. Revista Tamoios, v. 7, n. 1, p. 37-50, 2011. p. 43-44.

52 VITORELLI, E. Medidas estruturais extrajudiciais implementando mudanças estruturais pela via do consenso. In: VITORELLI, Edilson et al. Coletivização e unidade do direito. Londrina-PR: Editora Thoth, 2020. v. 2. p. 287-310. p. 302-303.

53 RODRIGUES, G. A. Ação Civil Pública e Termo de Ajustamento de Conduta: teoria e prática. 3. ed. Rio de Janeiro: Forense, 2011.

${ }^{54}$ DIDIER JR., F. et al. Elementos para uma teoria do processo estrutural aplicada ao processo civil brasileiro. Revista de Processo, São Paulo, v. 303, n. 5, p. 45-81, maio 2020. p. 53-55.
} 
o Grupo de Trabalho Interinstitucional sobre Educação Infantil (GTIEI) formado por diversas entidades públicas e privadas, incluindo a Defensoria Pública de São Paulo e Ministério Público, por meio da litigância estratégica complexa, contesta, por meio do Judiciário, o déficit de vagas, qualidade do ensino público, nível de investimento do Município em educação infantil. Nessa atuação, foram utilizados diversos instrumentos, dentre os quais: ações civis públicas, TAC para implementação de direitos, mandados de segurança para acesso e transparência nos dados públicos. ${ }^{55}$

\section{Considerações finais}

Diante do exposto, depreende-se o epistemicídio como um problema histórico que se reinventa a partir da estrutura burocrática institucional e da formação da sociedade, sobretudo brasileira, o que produz danos inestimáveis aos grupos contra hegemônicos, como a população negra. Tratar esse tipo de litígio, sem a realização de uma mudança paradigmática estruturante, resulta na oportunização para o seu ressurgimento com novas roupagens, ou pior, na não produção de alteração notável.

Os dados trazidos demonstram que, diante de um litígio estrutural, como o epistemicídio de narrativas negras, apenas a promulgação de lei federal ou decisão judicial favorável não se mostra suficiente para a erradicação do problema. Ao negar aplicação à lei, dá-se margem à perpetuação das consequências até hoje sentidas na pele desses sujeitos, pois decorre do passado escravocrata e colonial da história do Brasil.

Por outro lado, pode-se concluir que existem diversos instrumentos capazes de atuar ativamente na resolução desse litígio estrutural. Pensando o epistemicídio como um litígio estrutural, é possível promover uma educação antirracista e emancipadora considerando-se quais são as raízes intrínsecas e históricas para uma resolução eficaz, mediante a elaboração de um plano estratégico de atuação conjunta e gradual mediante diálogo fortalecido com as entidades, as instituições e todos os interessados.

Para a dissolução do problema do epistemicídio das narrativas negras no sistema educacional, sugerem-se como instrumentos extrajudiciais de eficácia estruturante: a) o acompanhamento da implementação dessa nova política pública da Lei n. ${ }^{\circ}$ 10.639/2003 por intermédio de procedimento administrativo (P.A.); b) a realização de audiências públicas para o levantamento de demandas sociais, especialmente dos movimentos negros; c) a celebração de soluções consensuais via compromisso de ajustamento de conduta, quando for o caso, com a valorização do diálogo interinstitucional; d) a expedição de recomendação estrutural, em caso de relutância na via consensual, para a adoção das medidas necessárias para a aplicação da lei, como a capacitação dos professores e a alteração de currículos; e e) em último caso, a propositura de ação judicial.

Com isso, conclui-se que é preciso uma atuação ativa e criativa das instituições competentes para combater o racismo nas suas incontáveis nuances, diante dos diversos danos causados às pessoas negras desde a escola. Quando realizada de forma estrutural, uma reforma do sistema educacional para incluir a história contra hegemônica pode ser de grande valia para o combate ao epistemícidio das narrativas negras. Por fim, salienta-se que não há uma receita certa e infalível para dissolução do problema, porém, conforme demonstrado, existem técnicas extrajudiciais vigentes que contribuem para a construção de uma perspectiva humanitária do sujeito negro no Brasil, a partir da sua retomada como Ser no sistema escolar.

${ }_{55}$ COSTA, S. H. Acesso à justiça: promessa ou realidade? Uma análise do litígio sobre creche e pré-escola no município de São Paulo. Civil Procedure Review, v. 7, n. 2, p. 38-68, maio/ago. 2016. p. 50-51. 


\section{Referências}

ARENHART, S. C. Decisões estruturais no direito processual civil brasileiro. Revista de Processo, São Paulo, v. 225, n. 38, p. 389-410, nov. 2013.

BOYNARD, L. M. Por uma desconstrução única de mundo: alternativas cartográficas para aplicação da Lei 10.639. Revista Tamoios, v. 7, n. 1, p. 113-124, 2011.

CABRAL, A. P. Pelas asas de Hermes: a intervenção do amicus curiae, um terceiro especial. Revista de Direito Administrativo, Rio de Janeiro, v. 234, p. 111-142, out. 2003.

CAMBI, E.; VASCONCELOS, J. A. Desjudicialização de políticas públicas e o Novo Código de Processo Civil: contributo do Ministério Público e da advocacia pública à solução extrajudicial de conflitos. $A \& C$ Revista de Direito Administrativo \& Constitucional, Curitiba, v. 16, n. 64, p. 225-251, abr. 2016.

CARNEIRO, A. S. A construção do outro como não-ser como fundamento do ser. 2005. Tese (Doutorado) - Faculdade de Educação, Universidade de São Paulo, São Paulo, 2005.

CARVALHO, S. N. Processos coletivos e políticas públicas: mecanismos para a garantia de uma prestação jurisdicional democrática. 2013. Dissertação (Mestrado em Direito) - Faculdade de Direito, Universidade de São Paulo, São Paulo, 2013.

CORREA, G. S. Conteúdos possíveis a partir da Lei 10.639: as geografias das comunidades remanescentes de quilombo no território brasileiro. Revista Tamoios, v. 7, n. 1, p. 37-50, 2011.

COSTA, S. H. Acesso à justiça: promessa ou realidade? Uma análise do litígio sobre creche e pré-escola no município de São Paulo. Civil Procedure Review, v. 7, n. 2, p. 38-68, maio/ago. 2016.

DIDIER JR., F. et al. Elementos para uma teoria do processo estrutural aplicada ao processo civil brasileiro. Revista de Processo, São Paulo, v. 303, n. 5, p. 45-81, maio 2020.

FREITAS, P. A Lei 10.639, o ensino de história e a cultura afro-brasileira. OPSIS, v. 10, n. 1, p. 15-28, 2010.

GILLAM, R. Learning to transgress: Law 10.639 and teacher training classrooms in São Paulo, Brazil. Transforming Anthropology, v. 24, n. 1, p. 70-79, 2016.

GRAVONSKI, A. A. Técnicas extraprocessuais de tutela coletiva: a efetividade da tutela coletiva fora do processo judicial. São Paulo: Editora Revista dos Tribunais, 2010.

GROSFOGUEL, R. A estrutura do conhecimento nas universidades ocidentalizadas: racismo/sexismo epistêmico e os quatro genocídios/epistemicídios do longo século XVI. Sociedade e Estado, Brasília, v. 31, n. 1, abr. 2016.

MARQUES, E. P. S. A implementação da Lei 10.639/03 no Estado de Mato Grosso do Sul e a formação continuada de professores: uma perspectiva emancipatória e decolonial. Revista Contemporânea de Educação, v. 12, n. 23, p. 51-68, 2017.

MAZZILLI, H. N. O inquérito civil: investigações do Ministério Público, compromissos de ajustamento e audiências públicas. São Paulo: Saraiva, 1999.

NEVES, C. S. O lixo vai falar: racismo, sexismo e invisibilidades do sujeito negro nas narrativas de direitos humanos. Revista Brasileira de Políticas Públicas, v. 10, n. 2, p. 124-141, 2020.

NJERI, A. Educação afrocêntrica como via de luta antirracista e sobrevivência na Maafa. Revista Sul-Americana de Filosofia e Educaşão (RES AFE), v. 31, p. 4-17, 2019.

NJERI, A. Reflexões artístico-filosóficas sobre a humanidade negra. Revista Ítaca, n. 36, p. 164-226, 2020. 
NUNES, L. S. et al. Dos litígios aos processos estruturais: pressupostos e fundamentos. In: FARIA, J. C. et al. (org.). Novas tendências, diálogos entre direito material e processo. Belo Horizonte: Editora D’Plácido, 2018. p. 365-383.

QUIJANO, A. A colonialidade do saber: eurocentrismo e ciências sociais. Buenos Aires: CLACSO, 2005.

RIBEIRO, K. Kemet, Escolas e Arcádeas: a importância da filosofia africana no combate ao racismo epistêmico e a Lei 10.639/03. 2017. Tese (Mestrado em Filosofia e Ensino) - Centro Federal de Educação Tecnológica, Rio de Janeiro, 2017.

ROCHA, G. H. C. Dificuldades para implementação da Lei 10.639: a influência dos valores religiosos sobre os temas apresentados no texto da lei. Revista Tamoios, v. 7, n. 1, p. 51-59, 2011.

RODRIGUES, G. A. Ação Civil Pública e Termo de Ajustamento de Conduta: teoria e prática. 3. ed. Rio de Janeiro: Forense, 2011.

SANTOS, R. E. M. et al. Scales of political action and social movements in education: the case of the Brazilian Black Movement and Law 10.639. Globalisation, Societies and Education, v. 14, n. 1, p. 30-48, 2016.

SANTOS, S. A. A Lei 10.639/03 como fruto da luta anti-racista do Movimento Negro. In: BRASIL. Educação anti-racista: caminhos abertos pela Lei Federal n. 10.639/03. Brasília: MEC/SECAD, 2005. p. 21-37.

VITORELLI, E. Levando os conceitos a sério: processo estrutural, processo coletivo, processo estratégico e suas diferenças. Revista de Processo, v. 284, n. 10, p. 333-369, out. 2018.

VITORELLI, E. Medidas estruturais extrajudiciais implementando mudanças estruturais pela via do consenso. In: VITORELLI, Edilson et al. Coletivização e unidade do direito. Londrina-PR: Editora Thoth, 2020. v. 2. p. 287-310.

ZENKNER, M. Ministério Público e solução extrajudicial de conflitos. In: RIBEIRO, C. V. A. (org.). Ministério Público: reflexões sobre princípios e funções institucionais. São Paulo: Atlas, 2010. 
Para publicar na revista Brasileira de Políticas Públicas, acesse o endereço eletrônico www.rbpp.uniceub.br

Observe as normas de publicação, para facilitar e agilizar o trabalho de edição. 